\title{
Rehabilitation in Endocrine Patients: A Novel Psychosomatic Approach
}

\author{
Nicoletta Sonino a, b, d Giovanni A. Fava ${ }^{c, d}$ \\ Departments of a Statistical Sciences and ${ }^{\mathrm{b}}$ Mental Health, University of Padova, Padova, and \\ 'Department of Psychology, University of Bologna, Bologna, Italy; ${ }^{\mathrm{d}}$ Department of Psychiatry, \\ State University of New York at Buffalo, Buffalo, N.Y., USA
}

\section{Key Words}

Rehabilitation - Endocrine disease $\cdot$ Quality of life $\cdot$

Pituitary disease $\cdot$ Cushing's syndrome $\cdot$ Acromegaly .

Thyroid disorders - Replacement therapy • Psychotherapy •

Physical therapy

\begin{abstract}
Long-standing endocrine disorders may imply a degree of irreversibility of the pathological process and induce highly individualized affective responses. The psychosocial impairment that is associated with incomplete remission from endocrine illness suggests the need for an innovative approach to treatment, introducing in clinical endocrinology the concept of rehabilitation, which in other fields of medicine is already established. This new proposal stems from a number of unresolved issues related to the high prevalence of psychosocial impairment in patients adequately treated for various endocrine conditions. Indeed, rehabilitation in endocrinology may be indicated in the following cases: (a) delayed recovery after appropriate treatment; (b) discrepancy between endocrine status and current functioning; (c) presence of a decline in physical and social functioning; (d) persistence of important comorbidity, with special reference to psychiatric disturbances; (e) assessment of abnormal illness behavior; (f) problems with lifestyle and risk behavior, and (g) potential role of stress in endocrine disturbances. The endocrine rehabilitation team should ideally include a trained
\end{abstract}

clinical endocrinologist, a physical therapist and a psychologist, with opportunities for other specialist consultations. The goal of such service would be to ensure education, support and specific interventions, helping the patient and his/ her family to achieve optimal coping with the difficulties of the recovery process. Due to its comprehensive psychosomatic characterization, this new approach would likely increase the chances of obtaining full recovery in a significant proportion of patients and has the potential of being costeffective.

Copyright $\odot 2007$ S. Karger AG, Basel

Long-standing endocrine disorders may imply a degree of irreversibility of the pathological process and induce highly individualized affective responses based on each patient's psychological assets and liabilities. In recent years there has been increasing awareness of the unsatisfactory degree of remission that current therapeutic strategies entail in a variety of endocrine disorders. The issues of psychological well-being, functional capacity, and social and interpersonal components of illness have provided new insights in clinical endocrinology [1-4]. Patients have become more aware of these issues and their difficulties in coping with endocrine illness and its often severe psychological consequences have led to the development of several patients' associations.

\section{KARGER}

Fax +4161306 1234 E-Mail karger@karger.ch www.karger.com

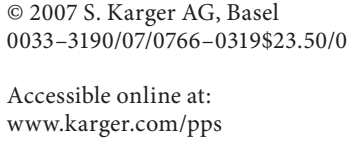

Nicoletta Sonino, MD

Department of Statistical Sciences, University of Padova

Via Battisti 241

IT-35121 Padova (Italy)

Tel. +39 049827 4189, Fax +39 049827 4170, E-Mail nicoletta.sonino@unipd.it 
New challenges are therefore emerging for patient management in clinical endocrinology. The psychosocial impairment that is associated with incomplete remission from endocrine illness requires novel modalities of clinical interventions, introducing the concept of rehabilitation in endocrinology, which is well established in other branches of internal medicine [5].

\section{Psychosocial Impairment in Patients Treated for Endocrine Disease}

Important psychiatric morbidity (particularly depression and anxiety) has been consistently reported in endocrine disorders and has long been recognized [6]. More recent has been the interest in impaired quality of life. While there is neither a precise nor agreed definition of quality of life, research in this area seeks essentially 2 kinds of information: the functional status of the individual and the patient's appraisal of health [7]. The concept stems from the fact that measures of disease status alone are insufficient to describe the burden of illness and that the subjective perception of health status (e.g., lack of well-being, demoralization, difficulties fulfilling personal and family responsibilities) is as valid as that of the clinician in evaluating outcome [7].

Psychiatric disturbances and impaired quality of life which were present in the acute phase of illness were often found to improve upon correction of hormonal imbalances [6]. Examples are provided by the favorable effects of steroid synthesis inhibitors (metyrapone, aminoglutethimide and ketoconazole) upon depression in Cushing's syndrome or antithyroid agents on anxiety in hyperthyroidism. However, disappearance of psychiatric symptoms and amelioration of quality of life are not always the case. In a recent investigation [1], 86 outpatients with pituitary disease cured or in remission for at least 9 months upon proper treatment by surgery, irradiation and/or pharmacological interventions were compared with 86 healthy subjects. A sample of 60 outpatients cured or in remission from nonpituitary endocrine disorders were also compared. Nearly 2 patients out of 3 , whether with pituitary or nonpituitary endocrine conditions, suffered from a psychiatric disorder. Both groups of patients displayed an impaired quality of life compared to controls [1]. The findings, which were obtained in a tertiary clinic, are consistent with an increasing body of literature that reports difficulties in obtaining full recovery in patients treated for endocrine disorders. This has been observed in recent studies concerned with patients with either pitu- itary disease at large $[8,9]$ or with individual conditions such as Cushing's disease [1, 10-13], acromegaly [1, 3, 1417], hyperprolactinemia $[1,19]$, nonfunctioning pituitary adenoma [20], hypopituitarism and adult growth hormone deficiency [2, 20-25], or with nonpituitary endocrine disorders, such as thyroid disturbances [4], primary hyperparathyroidism [26,27], polycystic ovary syndrome [28] and adrenocortical insufficiency [29].

There may be different reasons for a delayed or impaired process of recovery. Hormonal alterations are frequently associated with affective disturbances, which do not always remit upon normalization of blood parameters, as was found to be the case in Cushing's syndrome $[1,10-13]$ and thyroid disorders [4]. Hormone replacement may not fully restore optimal endocrine balance and subtle dysfunctions may still exert their influences on psychological states [30]. This has been observed particularly in hypopituitarism ensuing from the treatment of pituitary disease $[2,21,31]$.

Unrealistic hopes of 'cure' may foster discouragement and apathy. When surgery is performed (i.e., microadenomectomy in Cushing's disease), the patient is likely to have expectations of a quick recovery to his/her former normal condition. Harvey Cushing [32] emphasized the role of the physician in this difficult phase of illness: 'All clinicians are psychotherapeutists, and undoubtedly he is more successful with his patients who effectively uses this agency to allay the individual's morbid depression or doubts, anxiety or fears. A certain functional superstructure builds itself on even minor ailments. Of this we are all more or less appreciative. At times these so-called functional symptoms may be paramount, even when the associated organic lesion is more or less obvious; and some of us, with greater or less skill, may satisfactorily analyze and even partially dissipate them' (p. 967). Currently, the average endocrinologist is unfamiliar with the psychosocial aspects of patient care and lacks an adequate background, both in terms of personal skills and organizational structure, for facilitating the process of recovery.

\section{The Concept of Rehabilitation}

Rehabilitation of endocrine patients is here defined as the sum of activities required to ensure them the best physical, mental and social conditions so that they may progress towards an optimal state of health. By health we mean a 'state of complete physical, mental and social well-being and not merely the absence of disease or infir- 
mity', as defined by the World Health Organization [33] half a century ago.

Rehabilitation units and activities have achieved wide currency in many areas of medicine (e.g., cardiology, pneumology, rheumatology, neurology). Cardiac rehabilitation, which has been operational for at least 30 years, is probably the closest to the needs of clinical endocrinology.

Cardiac rehabilitation is indicated when, as a result of cardiac disease, a discrepancy occurs between current and optimal functioning and/or when changeable risk behavior exists [34]. The goals are to promote secondary prevention and to improve quality of life. Cardiac rehabilitation can cost-effectively reduce mortality and morbidity for patients with many types of cardiac disease [35]. Its beneficial effects include a reduction in the rate of death from cardiovascular disease, fewer cardiac symptoms, improved exercise tolerance, improved lipid levels, decreased cigarette smoking, improvement in psychological well-being and increased likelihood of returning to work [35]. Rehabilitation involves a multidisciplinary team that focuses on education, individually tailored exercise, risk factor modification and the optimization of functional status and mental health $[34,35]$.

Clinical endocrinologists are increasingly recognized as an important component of rehabilitation teams involved with traumatic brain injury, due to the high frequency of hypopituitarism [36-38], but have not developed their own rehabilitation services as yet.

\section{Rehabilitation in Endocrinology}

Rehabilitation may be indicated in the following cases.

(a) Delayed recovery after appropriate treatment: after a surgical intervention is performed (e.g., pituitary microadenomectomy in Cushing's disease), recovery has a slow pace and requires that all different problems are properly addressed $[1,6,10-13]$. Similar patterns characterize radiotherapy. Delayed recovery is thus a major indication for referral.

(b) Discrepancy between endocrine status and current functioning: quality of life and physical functioning may be seriously compromised even when the patient is apparently doing fine by a hormone viewpoint $[1-4,6,8-$ 29]. Research on quality of life has frequently emphasized the discrepancies in health perceptions between patients, their companions and their treating physicians [39]. This particularly applies to patients receiving replacement therapy $[6,30]$.

Rehabilitation in Endocrine Patients (c) Presence of a decline in physical and social functioning: endocrine disorders and diabetes may be associated with a deterioration of aspects of a patient's life encompassing family, interpersonal relationships, work and leisure $[1-4,6,8-29,40]$. Clinical recognition of specific problems may provide an opportunity to increase the level of functioning.

(d) Persistence of important comorbidity with special reference to psychiatric disturbances: endocrine disorders are associated with substantial physical and mental comorbidity. For instance, persistent joint-related complaints cause reduced quality of life after remission for acromegaly [41]. Major depression is a severe and lifethreatening complication of several endocrine disorders [6]. In pituitary-dependent Cushing's disease, the presence of depression was found to entail prognostic value [42]. The standard endocrine outpatient clinic is not geared to handling these complex clinical situations.

(e) Assessment of abnormal illness behavior: residual symptoms after successful treatment may be amplified by illness behavior, that is the ways in which individuals experience, perceive, evaluate and respond to their health status [6]. Lipowski [43] remarks that once the symptoms of a somatic disease are perceived by a person, 'then this disease related information gives rise to psychological responses which influence the patient's experience and behavior as well as the course, therapeutic response and outcome of a given illness episode' (p. 483). The study of illness behavior has important implications in clinical endocrinology [6]. It includes aspects such as compliance with medical treatment, difficulties in self-management [44], and the tendency to experience and communicate psychological distress in the form of physical symptoms which add on endocrine aspects. This latter phenomenon was found to occur in about 1 out of 5 of remitted endocrine patients [1].

(f) Problems with lifestyle and risk behavior: an increasing body of evidence links the progression of several medical disorders to specific lifestyle behaviors [45]. In recent years, several major controlled clinical trials have shown that type 2 diabetes can be delayed or prevented in people at high risk [46]. Similarly, a number of psychological treatments have been shown to be effective in health-damaging behaviors, such as smoking [47].

(g) Potential role of stress in endocrine disturbances: the psychoneuroendocrine balance between health and disease may be affected by allostatic load exceeding personal resources. The allostatic load is the cost of chronic exposure to fluctuating or heightened neuroendocrine response resulting from repeated or chronic environ-

Psychother Psychosom 2007;76:319-324 
mental challenge that an individual reacts to as being particularly stressful $[48,49]$. This information may be crucial in assessing patients with mild alterations in laboratory findings (e.g., slightly elevated prolactin levels), in clinical decisions, such as termination of the long-term pharmacological treatment of hyperprolactinemia, and in the presence of unexplained somatic symptoms or delayed recovery. Allostatic load can be decreased by lifestyle modification [45].

\section{The Functioning of an Endocrine Rehabilitation Service}

The interdisciplinary team approach has emerged as the mainstay of rehabilitation processes $[34,35]$. The endocrine rehabilitation team should ideally include a trained clinical endocrinologist, a physical therapist and a psychologist, with opportunities for consultations by other specialists.

The operational characteristics of the rehabilitation endocrinologist, however, depart from the standard approach in an endocrine clinic. In clinical endocrinology, there is often the tendency to rely exclusively on 'hard data', preferably expressed in the dimensional numbers of hormone values, excluding 'soft information', such as disability and well-being. This soft information, however, can now be reliably assessed $[45,50]$. The evidence that has accumulated on treatment of growth hormone deficiency $[2,21-25]$ should lead endocrinologists to a multidimensional consideration of treatment effects, encompassing also psychosocial parameters. For instance, the differential effects on quality of life that are entailed by differences in replacement therapy are frequently acknowledged in the newsletters of patients' associations and are receiving increasing research attention $[6,51-56]$. Adequate communication between endocrinologist and patient should be assured, with opportunities for discussion, negotiation and clarification, based on adequate assessment of all relevant biological, psychological, social and cultural factors. Multidimensional assessment should therefore inform replacement therapy in this setting.

The physical therapist may supervise gradual physical activity and devise appropriate strategies for contrasting physical and functional decline. Inactivity is a serious enemy of the postsurgical recovery process. Patients may postpone their participation in usual activities. However, avoiding situations that induce undue discomfort and anxiety initially relieves the distress but subsequently results in its further increase and perpetuation. Thus, it is important for the patient to go back to all previous activities with a graded schedule.

The role of the psychologist, as in cardiac rehabilitation $[34,35]$, is essential for a more precise definition of the patient's psychological symptoms (depression, anxiety disorders, irritable mood, etc.), for understanding coping difficulties and for modifying risk behavior (e.g., smoking). Brief forms of individual psychotherapy may be indicated in selected cases. Group therapy of patients sharing similar disorders (e.g., pituitary disease) might also be helpful. The patient would then be encouraged to put into words his/her feelings about the endocrine disease and its feared consequences. Emotional sharing, reassurance, the provision of information (with the endocrinologist participating in some sessions), and planning for the future would encourage the patient to think in terms of adaptive coping, rather than brood about the past ('I am no longer the person I used to be') and the potential dangers and disabling effects of his/her endocrine disease. In a pilot study [57], group therapy proved to be beneficial for women with climacteric syndrome. The psychologist may also offer advice and support to spouses and family members of patients undergoing the various phases of illness.

Sources of referral for the service do not only encompass endocrinology, neurosurgery and surgery divisions but may extend to primary care physicians, other specialists and patients' associations. An endocrine rehabilitation service would thus have the potential of substantially increasing the interactions between endocrinology and other medical fields.

\section{Conclusions}

As it happened in other types of rehabilitation $[5,34$, 35], the evidence which has accumulated on the psychosocial aspects of endocrine disease and on its process of recovery provides factual support to the concept of endocrine rehabilitation and to the introduction of such service. It may prove to be both cost-effective and an ideal setting for research and teaching. An interdisciplinary rehabilitation team may provide a coordinated approach to ensure adequate communication, education and support, to help the patient and his or her family achieve optimal coping with endocrine illness, and to implement gradual physical activity, with the aim of obtaining full recovery. This new approach with comprehensive psychosomatic care has the potential of reducing residual symptomatology and increasing the level of remission in a significant proportion of patients. 


\section{References}

1 Sonino N, Ruini C, Navarrini C, Ottolini F, Sirri L, Paoletta A, Fallo F, Boscaro M, Fava GA: Psychosocial impairment in patients treated for pituitary disease. Clin Endocrinol, in press.

$\checkmark 2$ Woodhouse LJ, Mukherjee A, Shalet SM, Ezzat S: The influence of growth hormone status on physical impairments, functional limitations, and health-related quality of life in adults. Endocr Rev 2006;27:287-317.

$\checkmark 3$ Webb SM: Quality of life in acromegaly. Neuroendocrinology 2006;83:224-229.

- 4 Watt T, Groenvold M, Rasmussen AK, Bonnema SJ, Hegedus L, Bjorner JB, Rasmussen UF: Quality of life in patients with benign thyroid disorders: a review. Eur J Endocrinol 2006;154:501-510.

5 Levack WMM, Taylor K, Siegert RJ, Dean JG: Is goal planning in rehabilitation effective? A systematic review. Clin Rehabil 2006;20: 739-755.

-6 Sonino N, Fava GA: Psychological aspects of endocrine disease. Clin Endocrinol 1998;49: $1-7$.

7 Leplege A, Hunt S: The problem of quality of life in medicine. JAMA 1997;278:47-50.

-8 Johnson MP, Woodburn CJ, Vance ML: Quality of life in patients with a pituitary adenoma. Pituitary 2003;6:81-87.

-9 Flitsch J, Spitzner S, Ludecke DK: Emotional disorders in patients with different types of pituitary adenomas and factors affecting the diagnostic process. Exp Clin Endocrinol Diabetes 2000;108:480-484.

10 Heald AH, Ghosh S, Bray S, Gibson C, Anderson SG, Buckler H, Fowler HL: Longterm negative impact on quality of life in patients with successfully treated Cushing's disease. Clin Endocrinol 2004;61:458-464.

11 Van Aken MO, Pereira AM, Biermasz NR, Van Thiel SW, Hoftijzer HC, Smit JWA, Roelfsema F, Lamberts SWJ, Romijn JA: Quality of life in patients after long-term biochemical cure of Cushing's disease. J Clin Endocrinol Metab 2005;90:3279-3286.

- 12 Sonino N, Bonnini S, Fallo F, Boscaro M, Fava GA: Personality characteristics and quality of life in patients treated for Cushing's syndrome. Clin Endocrinol 2006;64: 314-318.

13 Lindsay JR, Nausel T, Baid S, Gumowski J, Nieman LK: Long-term impaired quality of life in Cushing's syndrome despite initial improvement after surgical remission. J Clin Endocrinol Metab 2006;91:447-453.

14 Kauppinen-Mäkelin R, Sane T, Sintonen H, Markkanen H, Välimäki MJ, Löyttyniemi E, Niskanen L, Reunanen A, Stenman UH, Finnish Acromegaly Study Group: Quality of life in treated patients with acromegaly. J Clin Endocrinol Metab 2006;91:3891-3896.
15 Hua SC, Yan YH, Chang TC: Associations of remission status and lanreotide treatment with quality of life in patients with treated acromegaly. Eur J Endocrinol 2006;155:831837.

16 Trepp R, Everts R, Stettler C, Fischli S, Allemann S, Webb SM, Christ ER: Assessment of quality of life in patients with uncontrolled vs. controlled acromegaly using the Acromegaly Quality of Life Questionnaire (AcroQoL). Clin Endocrinol 2005;63:103-110.

17 Paisley AN, Rowles SV, Roberts ME, Webb SM, Badia X, Prieto L, Shalet SM, Trainer PJ: Treatment of acromegaly improves quality of life, measured by AcroQoL. Clin Endocrinol, in press.

18 Sonino N, Scarpa E, Paoletta A, Fallo F, Boscaro M: Slow-release lanreotide treatment in acromegaly: effects on quality of life. Psychother Psychosom 1999;68:165-167.

$\rightarrow 19$ Reavley A, Fisher AD, Owen D, Creed FH, Davis JRE: Psychological distress in patients with hyperprolactinemia. Clin Endocrinol 1997;47:343-348.

20 Dekkers OM, Van der Klaauw AA, Pereira AM, Biermasz NR, Honkoop PJ, Roelfsema F, Smit JWA, Romijn JA: Quality of life is decreased after treatment for nonfunctioning pituitary macroadenoma. J Clin Endocrinol Metab 2006;91:3364-3369.

21 Bulow B, Hagmar L, Orbaek P, Osterber K, Erfurth EM: High incidence of mental disorders, reduced mental well-being and cognitive function in hypopituitary women with GH deficiency treated for pituitary disease. Clin Endocrinol 2002;56:183-193.

22 Malik IA, Foy P, Wallmahmed M, Wilding JPH, MacFarlane IA: Assessment of quality of life in adults receiving long-term growth hormone replacement compared to control subjects. Clin Endocrinol 2003;59:75-81.

23 Rosilio M, Blum WF, Edwards DJ, Shavrikova EP, Valle D, Lamberts SW, Erfurth EM, Webb SM, Ross RJ, Chihara K, Henrich G, Herschbach P, Attanasio AF: Long-term improvement of quality of life during growth hormone $(\mathrm{GH})$ replacement therapy in adults with GH deficiency, as measured by questions on life satisfaction-hypopituitarism (QLS-H). J Clin Endocrinol Metab 2004;89: 1684-1693.

24 Saller B, Mattson AF, Kann PH, Koppeschaar HP, Svensson J, Pompen M, Koltowska-Haggstrom M: Healthcare utilization, quality of life and patient-reported outcomes during two years of GH replacement therapy in GH-deficient adults. Eur J Endocrinol 2006;154:843-850.

25 Koltowska-Haggstrom M, Mattson AF, Monson JP, Kind P, Badia X, Casanueva FF, Busschbach J, Koppeschaar HPF, Johannson G: Does long-term replacement therapy in hypopituitary adults with GH deficiency normalize quality of life? Eur J Endocrinol 2006;155:109-119.
26 Bollerslev J, Jansson S, Mollerup CL, Norderstrom J, Lundgren E, Torring O, Varhaug JE, Baranowsky M, Aanderud S, Franco C, Freyschuss B, Isaksen GA, Ueland T, Rosen T, SIPH Study Group: Medical observation, compared with parathyroidectomy, for asymptomatic primary hyperparathyroidism: a prospective, randomized trial. J Clin Endocrinol Metab 2007;92:1687-1692.

27 Walker MD, Silverberg SJ: Parathyroidectomy in asymptomatic primary hyperparathyroidism: improves 'bones' but not 'psychic moans'. J Clin Endocrinol Metab 2007;92: 1613-1615.

28 Ching HL, Burke V, Stuckey BGA: Quality of life and psychological morbidity in women with polycystic ovary syndrome. Clin Endocrinol 2007;66:373-379.

29 Thomsen AF, Kvist TK, Andersen PK, Kessing LV: The risk of affective disorders in patients with adrenocortical insufficiency. Psychoneuroendocrinology 2006;31:614622.

-30 Romijn JA, Smit JWA, Lamberts SWJ: Intrinsic imperfections of endocrine replacement therapy. Eur J Endocrinol 2003;149: 91-97.

- 31 Zenker S, Haverkamp F, Klingmuller D: Growth hormone deficiency in pituitary disease: relationship to depression, apathy and somatic complaints. Eur J Endocrinol 2002; 147:165-171.

32 Cushing H: Psychic disturbances associated with disorders of the ductless glands. Am J Insanity 1913;69:965-990.

33 World Health Organization: World Health Organization Constitution. Geneva, World Health Organization, 1948, p 28.

34 Donker FJF: Cardiac rehabilitation. Clin Psychol Rev 2000;20:923-943.

35 Dafoe W, Huston P: Current trends in cardiac rehabilitation. CMAJ 1997; 156:527532.

-36 Masel BE: Rehabilitation and hypopituitarism after traumatic brain injury. Growth Horm IGF Res 2004; 14 (suppl A):S108S113.

- 37 Klose M, Juul A, Poulsgaard L, Kosteljanetz M, Brennum J, Feldt-Rasmussen U: Prevalence and predictive factors of post-traumatic hypopituitarism. Clin Endocrinol 2007; 67:193-201.

38 Klose M, Juul A, Struck J, Morgenthalen NG, Kosteljanetz M, Feldt-Rasmussen U: Acute and long-term pituitary insufficiency in traumatic brain injury. Clin Endocrinol, in press.

-39 Sonino N, Fava GA, Fallo F, Boscaro M: Psychological distress and quality of life in endocrine disease. Psychother Psychosom 1990;54:140-144 
-40 Bayliss EA, Bayliss M, Ware JE, Steiner JF: Predicting declines in physical function in persons with multiple chronic medical conditions. Health Qual Life Outcomes 2004;2: 47.

-41 Biermasz NR, Pereira AM, Smit JWA, Romijn JA, Roelfsema F: Morbidity after longterm remission for acromegaly: persisting joint-related complaints cause reduced quality of life. J Clin Endocrinol Metab 2005;90: 2731-2739.

-42 Sonino N, Zielezny M, Fava GA, Fallo F, Boscaro M: Risk factors and long-term outcome in pituitary-dependent Cushing's disease. J Clin Endocrinol Metab 1996;81:2647-2652.

43 Lipowski ZJ: Physical illness and psychopathology. Int J Psychiatry Med 1974;5:483597.

-44 Keers JC, Liniks TP, Bouma J, Gans RO, ter Maaten JC, Wolffenbuttel BH, Sluiter WJ, Sanderman R: Do diabetologists recognize self-management problems in their patients? Diabetes Res Clin Pract 2004;66:157-161.

45 Fava GA, Sonino N: The clinical domains of psychosomatic medicine. J Clin Psychiatry 2005;66:849-858.

-46 Narayan KMV, Kanaya AM, Gregg EW: Lifestyle intervention for the prevention of type 2 diabetes mellitus. Treat Endocrinol 2003;2: 315-320.
47 Compas BE, Haagon DA, Keefe FJ, Leitenburg H, Williams D: Sampling of empirically supported psychological treatments from health psychology. J Consult Clin Psychol 1998;66:89-112.

48 McEwen BS: Protective and damaging effects of stress mediators. N Engl J Med 1998; 338:171-179.

49 Ryff CD, Dienberg-Love G, Urry HL, Muller D, Rosenkranz MA, Friedman EM, Davidson RJ, Singer B: Psychological well-being and ill-being: do they have distinct or mirrored biological correlates? Psychother Psychosom 2006;75:85-95.

50 Porcelli P, Sonino N (eds): Psychological Factors Affecting Medical Conditions. A New Classification for DSM-V. Adv Psychosom Med. Basel, Karger, 2007, vol 28.

51 Riedel M, Wiese A, Schurmeyer TH, Brabant G: Quality of life in patient's with Addison's disease: effects of different cortisol replacement methods. Exp Clin Endocrinol 1993; 101:106-111.

52 Bunevicius R, Kazanavicius G, Zalinkevicius R, Prange AJJ: Effects of thyroxine as compared with thyroxine plus triiodothyronine in patients with hypothyroidism. N Engl J Med 1999;340:424-429.
53 Razvi S, Ingoe L, Keeka G, Oates C, McMillan C, Weaver JU: The beneficial effect of L-thyroxine on cardiovascular risk factors, endothelial function, and quality of life in subclinical hypothyroidism. J Clin Endocrinol Metab 2007;92:1715-1723

54 Hunt PJ, Gurnell EM, Huppert FA, Richards C, Prevost AT, Wass JAH, Herbert J, Chatterjee VKK: Improvement in mood and $\mathrm{fa}$ tigue after dehydroepiandrosterone replacement in Addison's disease in a randomized, double-blind trial. J Clin Endocrinol Metab 2000;85:4650-4656.

55 Brooke AM, Kalingag LA, Miraki-Moud F, Camacho-Hübner C, Maher KT, Walker DM, Hinson JP, Monson JP: Dehydroepiandrosterone improves psychological wellbeing in male and female hypopituitary patients on maintenance growth hormone replacement. J Clin Endocrinol Metab 2006; 91:3773-3779.

56 Sobrinho LG: Psychopathology in endocrine disorders: why so persistent after the cure? Psychother Psychosom 2004;73:65-67.

57 Alder J, Besken KE, Armbruster U, Decio R, Gairing A, Kang A, Bitzen J: Cognitive-behavioural group intervention for climacteric syndrome. Psychother Psychosom 2006;75: 298-303. 